\title{
Gesneriaceae na Serra Negra, Minas Gerais, Brasil
}

\author{
Gesneriaceae of Serra Negra, Minas Gerais, Brazil
}

\author{
Juliana Gonçalves Blaser, ${ }^{1}$ Fátima Regina G. Salimena ${ }^{2,4}$ \& Alain Chautems ${ }^{3}$
}

\begin{abstract}
Resumo
A Serra Negra está inserida no complexo da Serra da Mantiqueira, na região sul da Zona da Mata de Minas Gerais. A vegetação da região é formada por um mosaico de campos rupestres e remanescentes de Floresta Ombrófila Alto-montana, Floresta Ombrófila Baixo-montana e Floresta Ombrófila Aluvial, entre altitudes de 900 a 1698m. A família Gesneriaceae está representada na área por 4 gêneros e 9 espécies: Anetanthus gracilis, Nematanthus crassifolius, N. lanceolatus, N. strigillosus, Sinningia cooperi, S. sceptrum, S. tuberosa, Vanhouttea brueggeri e $V$. hilariana. São apresentadas chave de identificação, descrições, ilustrações, distribuição geográfica e comentários taxonômicos das espécies.

Palavras-chave: Mata Atlântica, Serra da Mantiqueira, flora, taxonomia, campos rupestres, florestas nebulares.
\end{abstract}

\begin{abstract}
Serra Negra is part of the Serra da Mantiqueira mountain range, in the southern part of the "Zona da Mata" in Minas Gerais. Vegetation is composed of a mosaic of "campos rupestres" and remnants of Tropical Upland Rainforest, Tropical Lowland Rainforest and Alluvial Rainforest at altitudes varying from 900 to $1680 \mathrm{~m}$. The family Gesneriaceae is represented in the area by 4 genera and 9 species: Anetanthus gracilis, Nematanthus crassifolius, N. lanceolatus, N.strigillosus, Sinningia cooperi, S. sceptrum, S. tuberosa, Vanhouttea brueggeri and $V$. hilariana. An identification key for species, descriptions, illustrations, geographic distribution and taxonomic comments are provided.
\end{abstract}

Key words: Atlantic Forest, Mantiqueira Range, flora, taxonomy, rocky outcrops, cloud forests.

\section{Introdução}

A família Gesneriaceae está representada por 3.500 espécies incluídas em 140 gêneros (Weber 2004), com ampla distribuição nos trópicos e subtrópicos sendo pouco representada na África e com algumas espécies alcançando o sul da Europa. $\mathrm{Na}$ América tropical encontram-se cerca de 1.300 espécies e 60 gêneros (Burtt \& Wiehler 1995; Chautems 2003; Smith et al. 1997) com centro de diversidade no Nordeste da América do Sul. No Brasil são encontrados cerca de 210 espécies em 28 gêneros com uma grande diversidade de táxons no sudeste do Brasil (Chautems 1991; Chautems \& Kiyama 2003; Araújo et al. 2005; Araújo \&
Chautems 2010). É uma das principais famílias de epífitas na Mata Atlântica, com espécies de alto valor ornamental.

A Zona da Mata de Minas Gerais apresenta um grande número de pequenos remanescentes vegetacionais próximos entre si, ricos em espécies da fauna e flora com alto grau de endemismos, o que levou toda esta região, onde se insere a Serra Negra, a ser reconhecida como área prioritária para o conhecimento da diversidade biológica, estudos de conectividade entre fragmentos, estabelecimento de relações fitogeográficas e a avaliação do estado de conservação de suas diferentes formações vegetacionais (Costa et al. 1998; Drummond et al. 2005).

\footnotetext{
${ }^{1}$ Programa de Iniciação Científica, Universidade Federal de Juiz de Fora.

${ }^{2}$ Universidade Federal de Juiz de Fora, Instituto de Ciências Biológicas, Depto. Botânica, Campus Universitário, R. José Lourenço Kelmer s.n., Juiz de Fora, 36036-900, MG, Brasil.

${ }^{3}$ Conservatoire et Jardin Botaniques de la Ville de Genève, Chemin de l’Impératrice 1, CH-1292, Chambésy, Genebra, Suíça.

${ }^{4}$ Autor para correspondência: fatima.salimena@ufjf.edu.br
} 
A grande riqueza da flora desta região vem sendo documentada através de um amplo levantamento florístico realizado pela Universidade Federal de Juiz de Fora ( $<$ www.floraserranegra. com.br $>$ ), sendo que em apenas uma de suas formações, uma floresta de grota de cerca de 0,9 ha (Menini Neto et al. 2009) reuniu 157 espécies de plantas vasculares não-arbóreas, doze destas citadas na lista vermelha de espécies ameaçadas de extinção do estado de Minas Gerais (Biodiversitas 2007).

O presente trabalho teve como objetivo o conhecimento da família Gesneriaceae na Serra Negra, através da identificação das espécies, descrições, ilustrações, apresentação de chaves analíticas para as espécies, incluindo aspectos taxonômicos e distribuição geográfica, como contribuição para ações de preservação da biodiversidade desta região.

\section{Material e Métodos}

A Serra Negra está representada por um complexo de serras delimitado a oeste pelo município de Bom Jardim de Minas e a leste por Santa Bárbara do Monte Verde, entre as coordenadas $21^{\circ} 58^{\prime}-22^{\circ} 05^{\prime} \mathrm{S} 43^{\circ} 53^{\prime}-43^{\circ} 49^{\prime} \mathrm{W}$. Pertence ao bioma Mata Atlântica e localiza-se na região da Zona da Mata de Minas Gerais, na vertente sul da porção centro-oeste do planalto da Serra da Mantiqueira, formando o corredor sudeste e integrando a área denominada Bom Jardim de Minas. Tal área é atualmente definida como prioritária para conservação biológica no estado por Costa et al. (1998) com indicações para implantação de unidades de conservação (Drummond et al. 2005).

O clima da região é do tipo Cwb de Köppen, mesotérmico úmido, com invernos secos e frios e verões brandos e úmidos, com precipitação media anual de $1886 \mathrm{~mm}$ (Valente et al. 2011).

A fitofisionomia da região está representada pelo predomínio dos campos rupestres e remanescentes de Floresta Ombrófila Altomontana, Floresta Ombrófila Baixo-montana e Floresta Ombrófila Aluvial entre altitudes de 900 a $1698 \mathrm{~m}$ (Valente et al. 2011).

O presente estudo faz parte do inventário florístico da região desenvolvido entre os anos de 2003 a 2010 pela Universidade Federal de Juiz de Fora. Os materiais desta coleção estão depositados no Herbário CESJ, desta instituição. Foram também analisadas as coleções de Gesneriaceae depositadas nos herbários G, MBM, RB, SP e SPF, UEC (acrônimos segundo Holmgren et al. (1990). Na citação do material examinado foram incluídas as coleções procedentes de outras localidades para complementar as descrições das espécies. $\mathrm{O}$ estudo dos frutos foi realizado com base no material adicional de outras regiões depositados no Herbário CESJ.

As descrições das espécies foram baseadas na terminologia morfológica das definições de Harris \& Harris (2001) e a distribuição geográfica das espécies foi baseada no material examinado e complementada com dados da literatura.

A descrição da família e os dados de distribuição geográfica seguiram Chautems \& Kyiama (2003) e Araújo et al. (2005).

\section{Resultados e Discussão}

Na Serra Negra a família Gesneriaceae está representada por nove espécies distribuídas em quatro gêneros: Anetanthus Hiern. (A. gracilis), Nematanthus Schrad. (N. crassifolius, $N$. strigillosus e N. lanceolatus), Sinningia Nees. (S. cooperi, S. sceptrum e S.tuberosa) e Vanhouttea Chautems (V. brueggeri e V. hilariana). São ervas e arbustos epífitos no interior de florestas, terrícolas ou campestres, ocorrendo nas diferentes formações florestais da Serra Negra.

Anetanthus gracilis apresenta ampla distribuição, ocorrendo por toda a América do Sul. As espécies de Nematanthus e Sinningia ocorrem na Floresta Atlântica do sudeste do Brasil (Chautems 1990, Chautems 1991), e as duas espécies de Vanhouttea estão restritas ao estado de Minas Gerais (Chautems 2002). Neste último padrão classificam-se as duas espécies do gênero encontradas na Serra Negra na categoria "Em perigo" (Biodiversitas 2007) seguindo os critérios estabelecidos pela IUCN, enquanto as demais espécies estão incluídas na categoria "Vulnerável".

A diversidade das espécies de Gesneriaceae encontradas na Serra Negra indica maior semelhança com os táxons desta família distribuídos na Cadeia do Espinhaço e na Serra do Brigadeiro, ao norte da área de estudo, do que com as espécies encontradas na Serra da Mantiqueira da qual a Serra Negra faz parte (Barros et al. 2010).

Gesneriaceae DC., Essai Prop. Med. Pl. 2:192. 1816.

Ervas, subarbustos ou arbustos, terrícolas, rupícolas, epífitas ou trepadeiras com sistema subterrâneo com raízes perenes, rizomatoso 
ou tuberoso; caule herbáceo ou lenhoso, ereto, escandente ou pendente. Folhas simples, opostas, $3(-4)$ verticiladas ou solitárias, iguais ou anisófilas, pecioladas ou subsésseis, peltadas ou não; lâmina com margem inteira, crenada ou serreada, membranácea a crassa. Inflorescência axilar ou terminal, cimosa, racemosa ou uniflora. Flores geralmente vistosas, pediceladas, gamopétalas, zigomorfas, raramente actinomorfas, bissexuadas, protrândricas, ressupinadas ou não; lacínios 5 , pouco unidas na base, às vezes $1 / 3$ ou quase $1 / 2$ do comprimento, verdes ou coloridas, inteiras ou denteadas; corola tubulosa ou tubuloso-gibosa, magenta, vermelha ou alaranjada, raramente alva, às vezes globosa na base, ou junto ao ápice, lobos subiguais ou desiguais, eretos ou patentes; estames 4, inclusos, raramente exertos, epipétalos, ocasionalmente estaminódio inconspícuo presente, anteras unidas, rimosas; disco anular constituído de 1-5 glândulas; ovário súpero a semi-ínfero, 2-carpelar, 1-locular, placentação parietal; estilete simples, estigma estomatomórfico ou $2-$ lobado. Fruto baga ou cápsula seca ou carnosa, 2-valvar; sementes numerosas, geralmente elípticas, estriadas.

\section{Chave para identificação das espécies de Gesneriaceae na Serra Negra, Minas Gerais}

1. Planta $5-14 \mathrm{~cm}$ de altura, flor menor que $10 \mathrm{~mm}$ compr., corola branca Anetanthus gracilis

1'. Planta 0,15-2 $\mathrm{m}$ de altura, flor com mais de $10 \mathrm{~mm}$ compr., corola alaranjada, vermelha ou magenta.

2. Ervas com tubérculos presentes, folha com margem crenada, inflorescência cimosa ou racemosa

3. Folhas emergindo do tubérculo ou de um caule reduzido, peltadas Sinningia tuberosa

3'. Folhas caulinares, não peltadas

4. Folhas 3(-4) verticiladas, lanceoladas, inflorescência racemo de cimeira, flores alaranjadas, corola $3,4-4,1 \mathrm{~cm}$ compr. Sinningia sceptrum

4'. Folhas opostas, oval-cordadas, inflorescência cimeira, flores vermelhas com base amarela ou maculada de roxo e branco, corola 5-5,8 cm compr. Sinningia cooperi

2'. Ervas ou subarbustos com tubérculos ausentes, folha com margem inteira ou serreada, inflorescência uniflora.

5. Folhas com margem serreada, corola vermelha ou magenta pintalgada de vináceo, não gibosa.

6. Pedicelo da flor 1,3-1,8 cm compr., lacínios do cálice lanceolado-lineares, 1,4-1,8 cm compr., corola arqueada $5-5,5 \mathrm{~cm}$ compr. Vanhouttea hilariana

6'. Pedicelo da flor 2,3-3,6 cm compr., lacínios do cálice lanceolados, 2,6-3,1 cm compr., corola reta $4,4-5,3 \mathrm{~cm}$. compr. Vanhouttea brueggeri

5'. Folhas com margem inteira, corola vermelha ou alaranjada, gibosa.

7. Pedicelo da flor $2,6-4,5 \mathrm{~cm}$ compr. Nematanthus crassifolius

7'. Pedicelo da flor $0,3-1,4 \mathrm{~cm}$ compr., corola alaranjada ou vermelha com lobos amarelos, 1,3-3,0 cm compr., fauce $0,4-0,7 \mathrm{~cm}$ diâm.

8. Pedicelo $0,9-1,4 \mathrm{~cm}$ compr., lacínios do cálice lanceolados, giba voltada para baixo Nematanthus strigillosus

8'. Pedicelo 0,3-0,6 cm compr., lacínios do cálice orbiculares a reniformes, giba voltada para cima Nematanthus lanceolatus

1.1 Anetanthus gracilis Hiern.,Vidensk. Meddel. Dansk. Naturhist. Foren. Kjobenhaven 18771878:93.1877.

Fig. 1a-c, 2a Ervas; 5-10(-14) cm. Folhas com pecíolo 2-6 mm compr.; lâmina $1-2,5 \times 0,5-1,2 \mathrm{~cm}$, papirácea, elíptica, ápice agudo, base atenuada, margem serreada, discolores, face adaxial verde, face abaxial verde-pálido, raro avermelhada, face adaxial pubescente, face adaxial esparsamente pubescente com tricomas concentrados nas nervuras. Inflorescência em cimeiras axilares com 2-6 flores, brácteas ausentes, pedúnculo 2-5 cm compr., pedicelo 4-6 $\mathrm{mm}$; cálice ca. 1-2 mm compr., verde, esparsamente pubescente, lacínios estreitamente lanceolados; corola 5-6 $\mathrm{mm}$ compr., branca, esparsamente pubescente, tubulosa, tubo ca. 1,2 mm diâm. com base ca. 1,5 mm larg., fauce ca. $2 \mathrm{~mm}$ diâm., lacínios desiguais, 2 superiores menores, ca. $2 \times 1,5 \mathrm{~mm}$, 3 inferiores maiores $3-3,5 \times 1,5 \mathrm{~mm}$; estames 
inclusos; ovário súpero, ovóide. Fruto com pedicelo até $12 \mathrm{~mm}$, cápsula, elipsóide, $4-5 \mathrm{~mm}$ compr., encoberto pelo cálice até um pouco mais da metade do comprimento.

Material examinado: Rio Preto, Serra Negra, II.2007, fl. e fr., N.L. Abreu et al. 135 (CESJ, UEC); Fazenda Mato Limpo, Gruta dos Macacos, III.2010, fl. e fr., $M$. Peixoto \& A. Chautems $28(\mathrm{G})$.

A. gracilis é uma espécie raramente coletada devido ao seu porte diminuto com flores pouco chamativas, apesar da sua ampla distribuição na América do Sul, ocorrendo da Colômbia até a Bolívia. No Brasil, está registrada no Distrito Federal e em Minas Gerais. Na Serra Negra cresce em afloramento rochoso coberto por musgos e líquens, em ambientes úmidos e sombrios ou na proximidade de grutas. $\mathrm{Na}$ área de estudo foi encontrada em flor no mês de fevereiro e março.

2.1 Nematanthus crassifolius (Schott) Wiehler, Selbyana 5:382. 1981. Fig. 1d, 2b Subarbustos; 0,5-2 m, caule glabro, raízes adventícias presentes ou ausentes; internós $0,7-4,8 \mathrm{~cm}$. Folhas opostas, anisofilas; pecíolo $0,2-1 \mathrm{~cm}$ compr., verde a avermelhado, glabro; lâmina 2,4-14 × 1,6-3,9 cm, crassa, ovada, elíptica ou oblanceolada, ápice acuminado, base cuneada, margem inteira, revoluta, levemente ciliada, discolores, face adaxial verde, face abaxial verde-pálido, raro avermelhada, glabra a esparsamente pubescente em ambas as faces; nervura central conspícua, 4-9 pares de nervuras secundárias, esparsamente pubescentes. Inflorescência uniflora, pendente, 1-2 flores na axila de brácteas; brácteas muito reduzidas, ca. $0,1 \mathrm{~cm}$, pubescentes, oblongas, margem inteira. Pedicelo 2,6-4,5 cm, verde a vináceo, pubescente; cálice 2,7-3,2 cm compr., verde a avermelhado, esparsamente pubescente, lacínios lanceolados, eretos, agudos, margem inteira; corola 4,7-6,5 cm compr., vermelha, pubescente, tubulosogibosa, comprimida lateralmente no ápice, giba pronunciada voltada para cima, lobos concolores revolutos, parte tubuloso-cilíndrica $0,5-0,8 \mathrm{~cm}$ compr., giba ca. $1,8 \mathrm{~cm} \times 3,8 \mathrm{~cm}$, fauce $1,8-2,2$ $\mathrm{cm}$ diâm., lacínios iguais, ca. 0,7 cm compr.; estames exertos, glabros; ovário súpero, cônico, pubescente. Fruto não visto.

Material examinado: Rio Preto, Serra Negra, V.2004, fl., F.R.G. Salimena et al. 1388 (CESJ, G); VIII.2004, fl., C.N. Matozinhos et al. 01 (CESJ, G); Cachoeira do Ninho da Égua, II.2006, fl., P.L. Viana 1933 \& N.F.O.
Mota (CESJ); Serra do Funil, trilha da ponte em direção ao serrote de São Gabriel, VI.2006, fl., F.R.G. Salimena et al. 1367 (CESJ).

Nematanthus crassifolius ocorre na região sudeste do Brasil, em Minas Gerais, Espírito Santo, Rio de Janeiro e São Paulo nas encostas das Serras do Mar e da Mantiqueira entre 400 e 1400m (Chautems 2003). Na Serra Negra é encontrada como epífita no interior de cânions ou de matas ciliares, em local sombreado e úmido. Encontrada em floração de fevereiro a outubro.

Morfologicamente, pertence ao grupo de espécies com flores pendente-ressupinadas, tendo como espécies mais proximamente relacionadas Nematanthus fluminensis (Vell.) Fritsch e $N$. brasiliensis (Vellozo) Chautems. No entanto, apenas $N$. crassifolius ocorre em Minas Gerais e é distinta destas espécies por apresentar folhas ovado-elípticas, cálice com lacínios lanceolados, eretos, esparsamente pubescentes e corola vermelha vistosa.

2.2 Nematanthus lanceolatus (Poir.) Chautems, Diss. Bot. 112:189. $1988 . \quad$ Fig. 1e, 2c

Subarbustos; $0,5-2 \mathrm{~m}$ alt., caule esparsamente pubescente a densamente pubescente próximo ao ápice; internós $0,9-5,2 \mathrm{~cm}$ compr. Folhas opostas, anisofilas; pecíolo $0,5-4,5 \mathrm{~cm}$ compr., vináceo, glabro; lâminas 3,6-10,4 × 3,6-1,5 cm, oblanceoladas a elípticas ou obovadas, ápice acuminado, base obliqua a cuneada, margem inteira, discolores, face adaxial verde, face abaxial creme a castanha, face adaxial esparso-pubescente, face abaxial densamente pubescente; nervura principal avermelhada, densamente pubescente, 4-5 pares de nervuras secundárias conspícuas na face abaxial, densamente pubescentes. Inflorescência uniflora, brácteas ausentes. Pedicelo 0,3-0,6 cm compr., ereto, vermelho, densamente pubescente; cálice $1-1,5 \times 1-1,4$ $\mathrm{cm}$, vináceo, esparsamente pubescente, lacínios orbiculares a reniformes, eretos, margem inteira; corola 2,5-3 cm compr., vermelha com lobos amarelos, face externa densamente tomentosa com tricomas alvos, face interna glabra a esparsamente pubescente, tubuloso-gibosa, base cilíndrica de ca. $0,5 \mathrm{~cm}$ diâm., tubo de ca. $0,8 \mathrm{~cm}$ compr. até chegar à giba pronunciada e voltada para cima, fauce estreita, ca. 0,7 cm diâm., lacínios iguais, ca. 0,2 cm compr.; estames ca. $1,4 \mathrm{~cm}$ compr., inclusos, glabros; ovário súpero, ovóide, pubescente. Fruto não visto. 

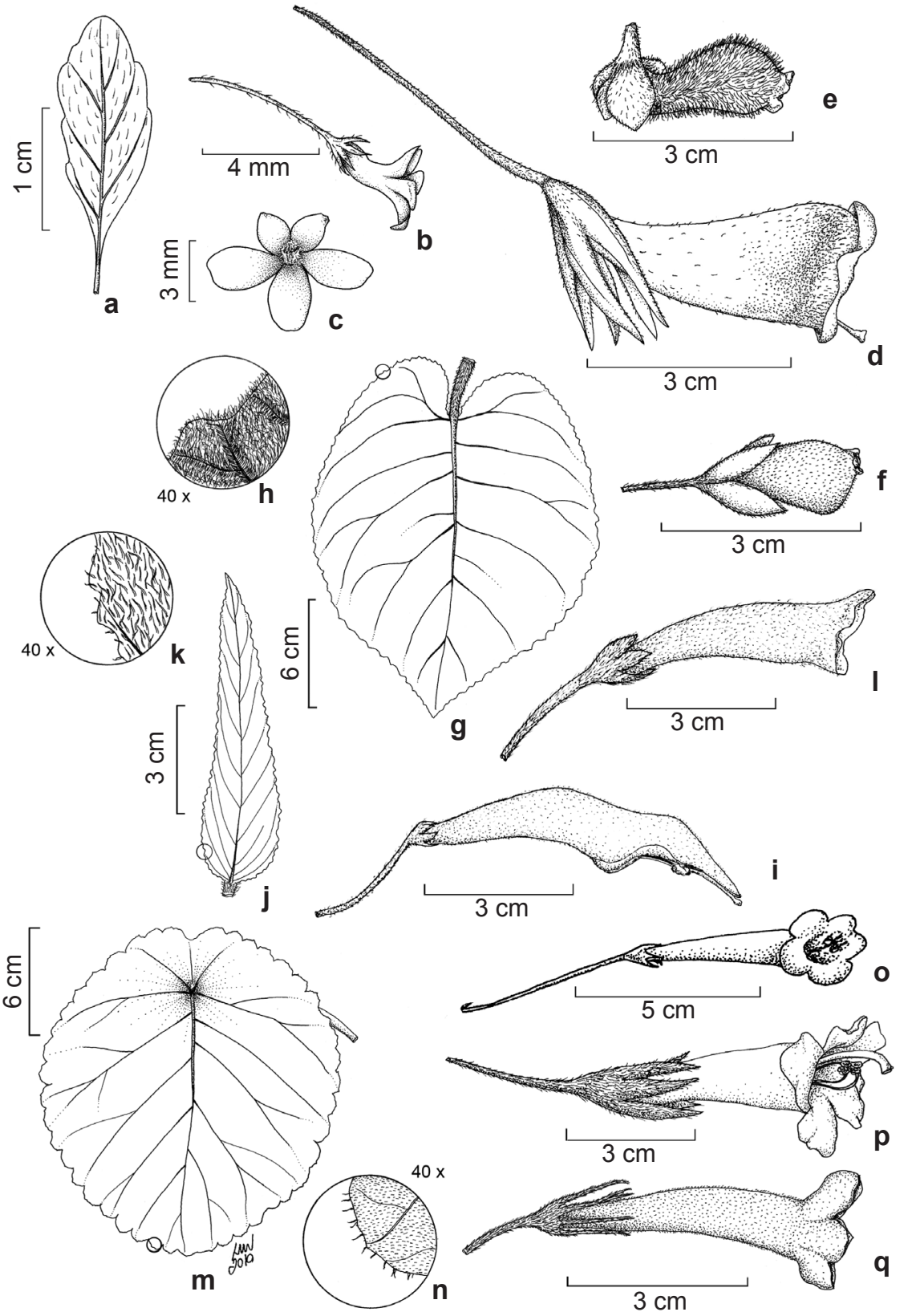

Figura 1 - a-c. Anetanthus gracilis - a. folha; b. flor, vista lateral; c. flor, vista frontal. d. Nematanthus crassifolius - flor. e. N. lanceolatus - flor, vista lateral. f. N. strigillosus - flor, vista lateral. g-i. Sinningia cooperi - g. folha; h. detalhe do indumento; i. flor, vista lateral. j-1. S. sceptrum - j. folha; k. detalhe do indumento; 1. flor, vista lateral. $\mathrm{m}-\mathrm{o}$. S. tuberosa - m. folha; n. detalhe do indumento; o. flor, vista lateral. p. Vanhouttea brueggeri - flor, vista lateral. q. V. hilariana - flor, vista lateral. (a-c Abreu et al. 135; d Matozinhos et al. 1; e Matozinhos et al. 251; f Belchior et al. 12; g-i Viana et al. 2016; j-1 Salimena et al. 2628; m-o Menini Neto et al. 666; p Feliciano et al. 31; q Salimena et al. 2657).

Figure 1 - a-c. Anetanthus gracilis - a. leaf; b. flower, lateral vist; c. flower, frontal vist. d. Nematanthus crassifolius - flower. e. N. lanceolatus - flower, lateral vist. f. N. strigillosus - flower, lateral vist. g-i. Sinningia cooperi - g. leaf; h. detail of indumentum; i. flower, lateral vist. j-1. S. sceptrum - j. leaf; k. detail of indumentum; 1. flower, lateral vist. m-o. S. tuberosa-m. leaf; n. detail of indumentum; o. flower, lateral vist. p. Vanhouttea brueggeri - flower, lateral vist. q. V. hilariana - flower, lateral vist. (a-c Abreu et al. 135; d Matozinhos et al. 1; e Matozinhos et al. 251; f Belchior et al. 12; g-i Viana et al. 2016; j-1 Salimena et al. 2628; m-o Menini Neto et al. 666; p Feliciano et al. 31; q Salimena et al. 2657). 
Material examinado: Serra Negra, cachoeira do Ninho da Égua, XI.2005, fl., C. Matozinhos et al. 251 (CESJ, $\mathrm{G})$; próximo à gruta do Funil, XI.2005, fl., K. Antunes et al. 201 (CESJ, G).

Nematanthus lanceolatus ocorre no sudeste do Brasil, em Minas Gerais, Espírito Santo e Rio de Janeiro (Araújo 2005). Recentemente foi encontrado em mata de altitude do sul da Bahia. $\mathrm{Na}$ Serra Negra é encontrada como epífita, rupícola ou terrícola em campos rupestres. Encontrada em floração nos meses de abril e novembro.

\subsection{Nematanthus strigillosus (Mart.) H.E. Moore,} Baileya 19:38. 1973.

Fig. 1f, 2d

Subarbustos ou ervas; ca. $50 \mathrm{~cm}$ alt., caule herbáceo, avermelhado, esparsamente estrigoso; internós $0,4-1,7 \mathrm{~cm}$ compr. Folhas opostas, levemente anisofilas; pecíolo 0,3-0,9 cm compr., verde a castanho, seríceo-tomentoso; lâminas 1,6-5,5 × 0,6-2 cm, crasso-rígidas, oblanceoladas a elípticas, ápice agudo a acuminado, base obtusa a cuneada, margem inteira, discolores, face adaxial verde, face abaxial castanha, estrigosa em ambas as faces; nervura principal conspícua, 3 pares de nervuras secundárias, inconspícuas, seríceo-tomentosas. Inflorescência uniflora, 1 flor na axila de 2 brácteas, pubescentes, lanceoladas a oblongas, margem inteira. Pedicelo 0,9-1,4 cm, densamente seríceo; cálice 1,3-1,7 × 0,4-0,6 $\mathrm{cm}$, verde a vermelho, pubescente, lacínios lanceolados, eretos, agudos margem inteira; corola 1,3-2,5 cm compr., alaranjada a vermelha com lobos amarelos, face externa pubescente, face interna glabra a esparsamente pubescente, tubuloso-gibosa, giba pronunciada voltada para baixo, base cilíndrica ca. $0,6 \mathrm{~cm}$ compr. $\times 0,4 \mathrm{~cm}$ diâm., fauce estreita, ca. 0,4 cm compr., lacínios eretos a patentes, diâm., iguais, arredondados, ca. $0,2 \times 0,3 \mathrm{~cm}$; estames ca. $0,9 \mathrm{~cm}$ compr., inclusos, glabros; ovário súpero, piriforme, densamente tomentoso. Fruto não visto.

Material examinado: Rio Preto, Serra da Caveira d'Anta, Fazenda Tiririca, II.2004, fl., A.J. Fernandes Júnior et al. 107 (CESJ, G); Serra Negra, trilha para o Ninho da Égua, IV.2005, fl., C.N. Matozinhos et al. 218 (CESJ); I.2006, fl., V. Belchior et al. 12 (CESJ).

Nematanthus strigillosus apresenta distribuição restrita aos campos rupestres das serras de Minas Gerais e no estado de São Paulo, nos campos de altitude entre 800 e $1800 \mathrm{~m}$, onde é considerada rara (Chautems 2003). Na Serra Negra ocorre nos campos rupestres, entre afloramentos quartzíticos. Encontrada em floração nos meses de janeiro, fevereiro e abril.

3.1 Sinningia cooperi (Paxton) Wiehler, Selbyana 1:32. 1975 .

Fig. 1g-i, 2e

Ervas; 30-40 cm alt., caule herbáceo, ereto a decumbente, densamente pubescente com tricomas vermelhos, tubérculo ca. $20 \mathrm{~cm}$ diâm,. Folhas opostas, não peltadas, levemente anisofilas, pecíolo 0,6-6,7 cm compr., hirsuto; lâmina 2,6-23 × 2,4-18 cm, crassa, ovalcordada, ápice agudo, base cordada, margem crenada, verde a avermelhada em ambas as faces, velutina a densamente velutina; 6-10 pares de nervuras secundárias, conspícuas, avermelhadas, densamente hirsutas. Inflorescência 4-7 cimeiras, com 1-6 flores na axila de brácteas, dispostas ao longo de uma raque de $15-45 \mathrm{~cm}$; pedúnculo 0,5-2 cm compr. Pedicelo 1,3-3,5 cm compr., hirsuto; cálice 0,4-0,7 cm compr., pubescentes, lacínios triangulares, tricomas triarticulados com articulações vermelhas; corola 5-5,8 cm compr., vermelha com base amarelada ou vermelha maculada de roxo e branco, pubescente externamente e glabra internamente, fortemente zigomorfa, 2 labiada, base intumescida com 5 protuberâncias em seguida levemente constrita, depois progressivamente alargada, 2 lobos dorsais unidos, eretos, 1,6-2,9 × 0,9-1,7 cm, 2 laterais $0,8-1,1 \times 0,8-1,2 \mathrm{~cm}, 1$ ventral $0,4-0,7$ cm compr.; estames ca. 4,9 cm compr., pouco mais curtos que o lábio superior, avermelhados, anteras unidas em disco; ovário súpero, alvo, densamente pubescente, ca. 0,8 cm compr., piriforme; nectário formado de 2 glândulas dorsais, unidas. Fruto não visto.

Material examinado: Serra Negra, trilha para o Ninho da Égua, IV.2005, fl., C.N. Matozinhos et al. 220 (CESJ, G); Cachoeira do Ninho da Égua, V.2006, fl., P.L. Viana et al. 2016 (CESJ, G).

Sinningia cooperi é uma espécie da Mata Atlântica, ocorrendo desde o Espírito Santo até Santa Catarina (Chautems 2003). Na Serra Negra é encontrada como epífita no interior de mata ou escandente sobre afloramentos. Encontrada em floração no mês de abril.

Espécie notável pelas flores bilabiadas e inflorescências densifloras. A densa pilosidade do caule e o comprimento menor das flores, a aproximam de Sinningia magnifica (Otto \& A. Dietr.) Wiehler; o que pode indicar uma possível introgressão entre esses dois táxons embora esta espécie não tenha sido coletada na área de estudo. 

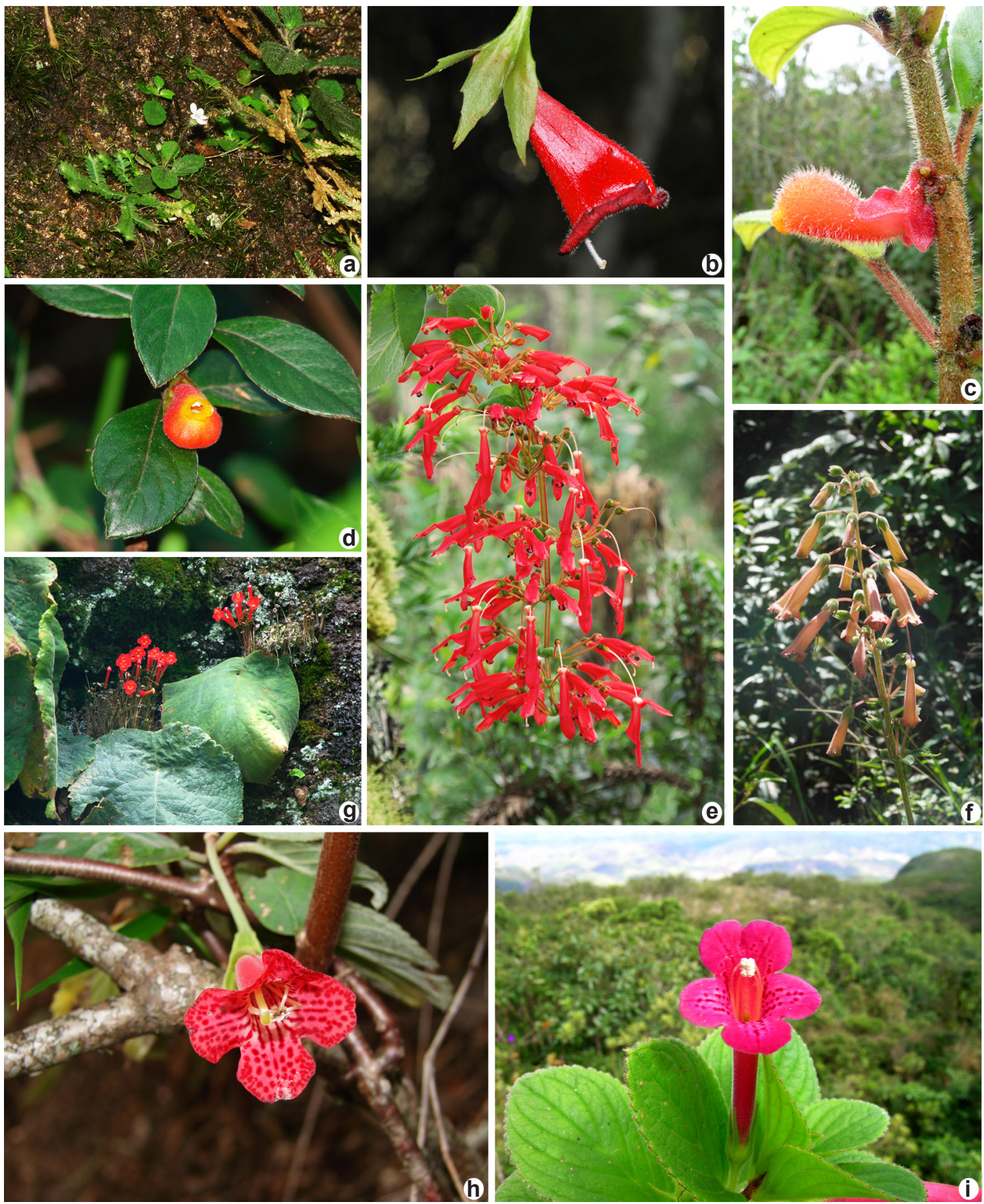

Figura 2 - Gesneriaceae na Serra Negra: a. Anetanthus gracilis Hiern., b. Nematanthus crassifolius (Schott) Wiehler, c. Nematanthus lanceolatus (Poir.) Chautems, Diss., d. Nematanthus strigillosus (Mart.) H.E. Moore, e. Sinningia cooperi (Paxton) Wiehler, f. Sinningia sceptrum (Mart.) Wiehler, g. Sinningia tuberosa (Mart.) H.E. Moore, h. Vanhouttea brueggeri Chautems, i. Vanhouttea hilariana Chautems

Figure 2 - Gesneriaceae of Serra Negra: a. Anetanthus gracilis Hiern., b. Nematanthus crassifolius (Schott) Wiehler, c. Nematanthus lanceolatus (Poir.) Chautems, Diss., d. Nematanthus strigillosus (Mart.) H.E. Moore, e. Sinningia cooperi (Paxton) Wiehler, f. Sinningia sceptrum (Mart.) Wiehler, g. Sinningia tuberosa (Mart.) H.E. Moore, h. Vanhouttea brueggeri Chautems, i. Vanhouttea hilariana Chautems. 
3.2 Sinningia sceptrum (Mart.) Wiehler, Selbyana 1: 32.1975 .

Fig. $1 \mathrm{j}-1,2 \mathrm{f}$

Ervas ou subarbustos; 0,5-2 m alt., caule herbáceo, ereto, verde com regiões vináceas, tomentoso, tubérculo presente. Folhas 3(-4) verticiladas, não peltadas, levemente anisofilas; pecíolo 0,2-0,4 cm compr.; lâmina 3,4-8,2 × 1,1-3,5 $\mathrm{cm}$, lanceoladas, ápice agudo a acuminado, base redonda a truncada, margem crenada, discolores, verde na face adaxial e castanha na face abaxial, face adaxial tomentosa, face abaxial densamente tomentosa; 7-10 pares de nervuras secundárias densamente pubescentes. Inflorescência racemo de cimeiras dispostas ao longo de um eixo terminal de 10,5-39 cm compr., 1-3(-4) flores na axila de brácteas verticiladas; pedúnculo inconspícuo, pedicelo 2,9-3,9 cm compr.; brácteas $0,3-1 \mathrm{~cm}$ compr., espatuladas, margem inteira. Pedicelo $0,7-$ $3,9 \mathrm{~cm}$ compr., verde a avermelhado, densamente pubescente; cálice $1-1,3 \times 0,3-0,5 \mathrm{~cm}$, verde a avermelhado, tomentoso, lacínios lanceolados; corola 3,4-4,1 cm compr., alaranjada, pubescente, tubulosa, fortemente zigomorfa, base intumescida com 2 protuberâncias salientes, em seguida levemente constrita e depois progressivamente alargada, lacínios subiguais, 2 superiores, unidos, eretos, $0,3 \times 0,8 \mathrm{~cm}$., 3 laterais, $0,2 \times 0,5 \mathrm{~cm}$.; estames exertos, anteras reunidas em retângulo; ovário súpero, vináceo, pubescente; nectário formado por 5 glândulas, as 2 dorsais mais desenvolvidas e unidas, as outras 3 pouco desenvolvidas e isoladas. Fruto cápsula loculicida 1,4-1,9 × 0,8-1 cm.

Material examinado: Rio Preto, Serra da Caveira D'anta, Fazenda Tiririca, II.2004, fl., F.R.G. Salimena et al. 959 (CESJ, G); Serra Negra, Ninho da Égua, IV.2005, fl., C.N. Matozinhos et al. 198 (CESJ); Serra Negra, Trilha para a cachoeira da divisa, II.2008, fl., F.R.G. Salimena et al 2628 (CESJ).

Material adicional examinado: Dias Tavares, V.1971, L. Krieger (CESJ 10511).

Sinningia sceptrum distribui-se do Sul da Bahia até o Rio de Janeiro (Chautems 1990). Na Serra Negra ocorre nos campos rupestres, sobre rochas ou em transição floresta-campo, geralmente em barranco úmido ou em solo encharcado. Encontrada em floração em fevereiro e abril

\subsection{Sinningia tuberosa (Mart.) H.E. Moore,} Baileya 19: 40. 1973.

Fig. $1 \mathrm{~m}-\mathrm{o}, 2 \mathrm{~g}$

Erva; $15-20 \mathrm{~cm}$ alt., caule reduzido com internós muito condensados, marrom-avermelhado, esparsamente pubescente, base tuberosa 2,1-3 cm larg. Folhas solitárias, peltadas, glutinosas emergindo da parte ereta do caule ou diretamente do tubérculo; pecíolo ca. $3,5 \mathrm{~cm}$ compr., marrom avermelhado; lâminas $17,5-19,5$ x 21,5-20 cm, orbiculares a reniformes, ápice arredondado a subagudo, base cordada, margem crenada, discolores, face adaxial verde, pubescente, face abaxial avermelhada, hirsuta; 5 pares de nervuras secundárias, conspícuas, castanhas. Inflorescência cimeira, 4-8 flores, brácteas de 0,1-0,2 cm compr., lanceoladaespatulada, pubescentes, margem inteira, vermelhas, pedúnculo 1,3-2,5 cm compr. Pedicelo 4-5,5 cm compr., marrom-avermelhado, pubescente; cálice $0,4-0,5 \mathrm{~cm}$ compr., verde a vináceo, glabro a hirsuto externamente, pubescente internamente, lacínios lanceolados; corola 2,9-3,2 cm compr., vermelhosangue com interior amarelado, face externa glabra a esparsamente pubescente, face interna glabra a esparsamente pubescente, tubulosa, base 5 gibosa, ligeiramente constrita, progressivamente alargada, fauce ca. $0,8 \mathrm{~cm}$ diâm., lacínios subiguais, $0,6-0,7$ $\mathrm{cm}$ compr.; estames inclusos ou atingindo a fauce; estaminódio presente, ca. $0,2 \mathrm{~cm}$ compr.; ovário súpero, ovóide; nectário formado por 2 glândulas dorsais adnatas ao ovário. Fruto cápsula loculicida, $1,2-1,9 \times 0,5-0,8 \mathrm{~cm}$, cálice aderido.

Material examinado: Rio Preto, Serra do Funil, IX.1989, fl., T.S.M. Grandi et al 2681 (SPF); Serra Negra, Gruta do Funil, VII.1989, fl., M.M.N. Braga 307 \& T.S.M Grandi (SPF), IV.2009, fl., L. Menini Neto et al. 666 (CESJ); Serra do Funil, margens do Rio do Funil na trilhas para o sumidouro, II.1999, fl., R.Mello Silva et al. 1653 (MBM, RB, SP, SPF); IV.2004, K. Antunes $79 \&$ C. Matozinhos (CESJ, G); Serra Negra, divisa com Santa Bárbara do Monte Verde, II.2006, fl., F.R.G. Salimena 2424 \& P.H. Nobre (CESJ).

Material adicional examinado: Juiz de Fora, Poço Dantas, II.1993, fr., Z.C. Viveiros \& M.S. Silveira (CESJ 26267).

S. tuberosa apresenta distribuição restrita aos campos rupestres de Minas Gerais, em altitudes acima de $1000 \mathrm{~m}$, saxícola ou rupícola formando grandes populações em paredões de quartzito. $\mathrm{Na}$ Serra Negra foi encontrada em floração nos meses de fevereiro, abril, julho e setembro.

É facilmente reconhecida por apresentar caule reduzido ou ausente e geralmente uma única grande folha peltada, emergindo diretamente do tubérculo.

4.1 Vanhouttea brueggeri Chautems, Candollea 261-270. $2002 . \quad$ Fig. 1p, $2 \mathrm{~h}$

Subarbusto; ca. $1 \mathrm{~m}$ alt., caule glabro a tomentoso no ápice, avermelhado internós 1,5-6 $\mathrm{cm}$ compr. Folhas opostas, iguais a levemente 
anisofilas, pecíolo $0,8-2,4 \mathrm{~cm}$ compr., seríceo; lâminas 3,3-8,4 × 1,4-4,6 cm, elípticas a ovadas, ápice agudo, base cuneada a obtusa, margem serreada, discolores, face adaxial verde escura, face abaxial verde clara, face adaxial pubescente, face abaxial incana; 5-8 pares de nervuras secundárias. Inflorescência uniflora, 1-2 flores em posição axilar acima dos nós. Pedicelo 2,3-3,6 cm compr.; cálice 2,6-3,1 cm compr., verde prateado, densamente seríceo, lacínios lanceolados, margem inteira; corola reta, completamente coberta pelos lacínios do cálice no botão, 4,4-5,3 cm compr., vermelha, pintalgada de roxo na face interna dos lobos, face externa lanulosa, face interna glabra a esparsamente pubescente, tubulosa, inflada na base, brevemente constrita, seguindo um diâmetro regular de ca. $0,7 \mathrm{~cm}$. até chegar à fauce de ca. $0,8 \mathrm{~cm}$, lobos desiguais, 2 dorsais fundidos, ca. $1,1 \times 1 \mathrm{~cm}$ compr., 3 ventrais livres ca. $0,7 \times$ $1,1 \mathrm{~cm}$ compr.; estames 4 , ca. 4,3 cm compr., inclusos, amarelos, glabros; estaminódio presente; ovário ínfero, pubescente; nectário formado por 5 glândulas isoladas.

Material examinado: Lima Duarte, Monte Verde de Cima, Serra Negra, III.1991, fl., M.C. Bruegger \& H.G. Souza (CESJ 24699[a]-holotipus e CESJ 24699[b]isotipus); Fazenda da Água Amarela, fl., E.A. Feliciano et al 31 (CESJ).

Vanhouttea brueggerii é uma espécie com endemismo restrito ao sul de Minas Gerais, ocorrendo nos municípios de Bom Jardim de Minas, Lima Duarte e Olaria. Na Serra Negra é uma espécie dos campos rupestres de areia quartzosa. Encontrada em floração no mês de março.

4.2 Vanhouttea hilariana Chautems, Candollea 261-270. 2002.

Fig. 1q, $2 \mathrm{i}$

Subarbusto; ca. $1 \mathrm{~m}$ alt., caule, glabro a tomentoso no ápice, avermelhado internós 1,3-2,8 $\mathrm{cm}$ compr. Folhas opostas a 3-verticiladas, iguais a levemente anisofilas, pecíolo $0,4-0,7 \mathrm{~cm}$ compr., pubescente a tomentoso; lâminas 2,5-5,0 $\times$ 2-3,2 cm, obovadas a ovais, ápice redondo, base cuneada a obtusa, margem serreada, discolores, face adaxial verde, face abaxial verde clara a amarelada, ambas as faces esparsamente hisutas; 4-5 pares de nervuras secundárias, curvadas, as basais aproximando-se do ápice. Inflorescência uniflora, 1-2 flores em posição axilar acima dos nós. Pedicelo 1,3-1,8 cm compr.; cálice ca. 1,4 x 1,8 cm compr., densamente seríceo, lacínios lanceolado-lineares; corola arqueada, nunca coberta completamente pelos lacínios do cálice no botão, 5-5,5 cm compr., magenta, pintalgada de vináceo na face interna dos lobos, face externa lanulosa, face interna glabra a esparsamente pubescente, tubulosa, inflada na base, brevemente constrita, seguindo um diâmetro regular de ca. $0,7 \mathrm{~cm}$ até chegar à fauce de ca. $0,8 \mathrm{~cm}$, lacínios desiguais, 2 dorsais fundidos $1,3 \times 1,2 \mathrm{~cm}$., 3 ventrais livres $1 \times 1 \mathrm{~cm}$; estames ca. $4,9 \mathrm{~cm}$ compr., exertos, amarelos, glabros; estaminódio presente; ovário súpero, densamente pubescente; nectário formado por 4 glândulas próximas ao ovário e uma isolada. Fruto cápsula loculicida, $1,6-1,8 \times 0,8-1 \mathrm{~cm}$.

Material examinado: Rio Preto, Serra da Caveira d'anta, II.2004, fl., F.R.G. Salimena et al. 353 (CESJ, G); Serra Negra, I.2006, C.N. Matozinhos et al. 156 (CESJ); Fazenda Serra Negra, II.2008, fl., F.R.G. Salimena 2657 (CESJ); Trilha do Marciano, IV.2004, fl., C.N. Matozinhos et al. 225 (CESJ); Vilarejo do Funil, X.2004, fl., F.R.G. Salimena et al. 1275 (CESJ, G).

Material adicional examinado: Carangola, Serra do Brigadeiro, II.1989, fr., B. Cosensa (CESJ 23462).

Vanhouttea hilariana apresenta endemismo restrito no estado de Minas Gerais, ocorrendo em poucas localidades na encosta Norte da Serra da Mantiqueira (Chautems 2002). Na Serra Negra é uma espécie típica dos campos rupestres arenosos. Encontrada em floração nos meses de fevereiro, abril e outubro.

Espécie muito semelhante a Vanhouttea brueggeri que, entretanto apresenta pecíolos 0,8 $2,4 \mathrm{~cm}$. compr., lacínios do cálice conspicuamente triangulares, folhas com pilosidade densa e nervuras secundárias formando um ângulo menor que $90^{\circ} \mathrm{com}$ a nervura principal.

\section{Agradecimentos}

Os autores agradecem ao programa de Pós Graduação em Ecologia da Universidade Federal de Juiz de Fora o apoio nos trabalhos de campo; ao biólogo Luiz Menini Neto as ilustrações e revisão do manuscrito; aos curadores dos herbários citados o empréstimo de material; à FAPEMIG o apoio financeiro (processos CRA 1891/06 e CRA-APQ 1810-5.02/07).

\section{Referências}

Araújo, A.O. \& Chautems, A. 2010. Gesneriaceae. Gesneriaceae In: Forzza, R.C. et al. (eds.). Catálogo de plantas e fungos do Brasil. Vol. 2 Instituto de Pesquisas Jardim Botânico do Rio de Janeiro, Rio de Janeiro. Pp. 1107-1115. 
Araújo, A.O.; Souza, V.C. \& Chautems, A. 2005. Gesneriaceae da Cadeia do Espinhaço de Minas Gerais, Brasil. Revista Brasileira de Botânica 14: 109-135.

Barros, M.J.G.; Mansano, V. F. \& Chautems, A. 2010. A família Gesneriaceae no Parque Nacional do Itatiaia, Brasil. Hoehnea 37: 131-145.

Biodiversitas. 2007. Revisão das listas das espécies da flora e da fauna ameaçadas de extinção do estado de Minas Gerais. Vol. 2. Fundação Biodiversitas, Belo Horizonte. Pp. 37-104. Disponível em <http:// www.biodiversitas.org.br/listas-mg $>$. Acesso em 15 Mar 2011.

Burtt, B. L. \& Wiehler. 1995. Classification of the family Gesneriaceae. Gesneriana 1:1-4.

Chautems, A. 1990. Taxonomic revision of Sinningia Ness: nomenclatural changes and new synonymes. Candollea 45: 51-59.

Chautems, A. 1991. A família Gesneriaceae na região cacaueira da Bahia, Brasil. Revista Brasileira de Botânica 14: 51-59.

Chautems, A. 2002. New Gesneriaceae from Minas Gerais, Brazil. Candollea 56: 261-270.

Chautems, A. \& Kiyama, C.Y. 2003. Gesneriaceae. In: Wanderley, M.G.L.; Shepherd, G.J.; Giuletti, A.M. \& Melhem, T.S. (eds.). Flora fanerogâmica do estado de São Paulo. Vol. 3. FAPESP, Rima, São Paulo. Pp. 75-103.

Costa, C.M.R.; Herrmann, G.; Martins, C.S.; Lins, L.V. \& Lamas, I.R. 1998. Biodiversidade em Minas Gerais: um atlas para a sua conservação. Fundação Biodiversitas, Belo Horizonte. 94p.
Drummond, G.M.; Martins, C.S.; Machado, A.B.M.; Sebaio, F.A. \& Antonini, Y. 2005. Biodiversidade em Minas Gerais: um atlas para sua conservação. 2ed. Fundação Biodiversitas, Belo Horizonte. $222 \mathrm{p}$.

Harris, J.G. \& Harris, M.W. 2001. Plant identification terminology - an illustrated glossary. Spring Lake Publishing, Utah. 206p.

Holmgren, P.K. \& Holmgren. 1988. Onwards (continuously update). Index Herbariorum. New York Botanical Garden. New York. Disponível em $<$ http//sciweb.nybg.org/science2/indexherbarium. asp>. Acesso em Mar 2011.

Menini, N. L.; Matozinhos, C. N.; Abreu, N. L.; Valente, A.S.M.; Antunes, K.; Souza, F.S.; Viana, P.L. \& Salimena, F.R.G. 2009. Flora vascular não-arbórea de uma floresta de grota na Serra da Mantiqueira, Zona da Mata de Minas Gerais, Brasil. Biota Neotropica 9: 149-161.

Smith, J.F.; Wolfram, J.C.; Brown, K.D.; Carrol, C.L. \& Denton, D.S. 1997. Tribal relationships in the Gesneriaceae: evidence from DNA sequences from the chloroplast ndhF. Annals of the Missouri Botanical Garden 84: 50-66.

Valente, A.S.M.; Garcia, P.O.; Salimena, F.R.G. \& Oliveira-Filho, A.T. 2011. Composição, estrutura e similaridade florística da Floresta Atlântica, na Serra Negra, Rio Preto, Minas Gerais, Brasil. Rodriguésia 62: 321-340.

Weber, A. 2004. Gesneriaceae. In: Kubitzki, K. \& Kadereit, J.W. (eds.). The families and genera of vascular plants. Vol. 7. Dicotyledons, Lamiales. Springer Verlag, Berlin. Pp 63-158. 